\title{
Maximizing the expected net future value as an alternative strategy to gamma discounting
}

\author{
Christian Gollier* \\ University of Toulouse
}

September 1, 2003

\begin{abstract}
We examine the problem of selecting the discount rate for far distant cash-flows when there is much uncertainty about what will be the future investment opportunities in the economy. We show that it is efficient to take a discount rate that is increasing with the time horizon, and that this rate should tend to the largest possible rate as the horizon tends to infinity. These recommendations are opposite to the ones proposed by Weitzman (2001) in this journal.
\end{abstract}

*This paper has benefitted from intense discussions with François Salanié and Richard Zeckhauser. 


\section{Introduction}

Suppose that we have to decide whether or not to implement an investment project whose rate of return is $1 \%$ per year with certainty. It is a very longterm project whose future benefits can be cashed only in a far distant future, say more than 200 years. There is much uncertainty about the rate of return of capital in the remaining of the economy. To keep it simple, suppose that experts are equally divided in two groups. In the first group, it is believed that the rate of return of capital will be a sizeable $5 \%$ per year. The second group of experts is pessimistic with a zero rate of return. The question is: should we invest in this long-term project that yields a sure $1 \%$ rate of return per year? To answer this question, one should use the standard arbitrage analysis which underlies the idea of discounting. Suppose that we have one dollar to spend today to improve the future. We then need to compare the sure future benefit of investing it in the above-mentioned project to the uncertain benefit of investing the same dollar in the capital market. In Table 1, we present these numbers for different time horizons, where $(x ; y)$ represents the two equally likely future payoffs of the capital market.

\begin{tabular}{c|cc} 
Time horizon & $\begin{array}{c}\text { Sure payoff } \\
\text { of the project }\end{array}$ & $\begin{array}{c}\text { Equally likely payoffs } \\
\text { of the capital market }\end{array}$ \\
\hline \hline 200 years & 7 & $\left(1 ; 17 \times 10^{3}\right)$ \\
500 years & 145 & $\left(1 ; 39 \times 10^{9}\right)$ \\
1000 years & $21 \times 10^{3}$ & $\left(1 ; 15 \times 10^{20}\right)$
\end{tabular}

Table 1: future cash-flow of one dollar invested in the project or in the market.

We see the power of compound interests at work in this simple exercise. This is particularly explicit for the $5 \%$ rate of return of the capital market if we are lucky. Telling what to do ex ante is not easy in this case because of the size of the risk on the capital market. Suppose that our time horizon for the investment project is 200 years. If we assume risk neutrality, it is obvious that it is optimal to invest in the market rather than in the project, since, on average, the future value generated by the market is 2,363 larger than the one of the project. Things are even clearer for longer horizons, with a ratio of expected future cash-flows of $2710^{7}$ for 500 years, and $7410^{15}$ for a millennium. We conclude that, if the representative agent is risk neutral, it is better not to invest in the project with a sure $1 \%$ rate of return. 
In this note, we reexamine this question of the long-term discount rate to be used for cost-benefit analysis of such important economic problem as global warming, nuclear wastes, and the management of exhaustible resources, for example. We show how to take into account of the considerable uncertainty surrounding the future rate of return on capital.

\section{The model}

Consider a sure investment project which requires one unit of the single consumption good at date 0 , and which generates a single payoff $Z$ at date $t$. $Z$ can be the reduction in damages due to global warming generated by a reduction in the current emission of greenhouse gases. These efforts are aimed at improving the welfare of the generation leaving at date $t$. A social planner is asked to determine whether or not to invest in this project. He learned in a good Business School that an investment project is desirable only in comparison to other investment opportunities. Those alternative investments are generically characterized by the risk-free rate of return $x$ of capital markets. Thus, he compares the final future payoff of the two investments at date $t$, i.e., he compares $Z$ to $e^{x t}$. In other words, he compares the return $t^{-1} \ln Z$ of the project to the return of the financial markets. Or, else, he computes the net future value $N F V=-e^{x t}+Z$. Investments are thus ranked according to their net future value.

So far, so good. Suppose now that the future risk-free rate of return of capital markets is uncertain. The planner and the experts believe that this rate will be constant in the future but, as of today, they don't know the level at which it will stabilize soon in the future. ${ }^{1}$ Let $\widetilde{x}$ denote the random variable characterizing this uncertainty. Its support is in $[-1,+\infty[$. Because the economy is neutral to risk, the planner extends the above decision rule to uncertainty in the following way.

Criterion 1 Different investment projects should be ranked according to their expected net future value.

This means that our project, when compared to doing nothing, should be implemented if $-E e^{\widetilde{x} t}+Z$ is positive. This is equivalent to requiring that the

\footnotetext{
${ }^{1}$ If the delay to get the information is relatively short, one should add some option value to wait into the cost-benefit analysis. See Ingersoll and Ross (1992).
} 
future payoff $Z$ be larger than the expected payoff of investing the money on the capital market. Observe that one can define an equivalent per period interest rate $R$ that would do the same job. Indeed define $R(t)$ in such a way that

$$
e^{R(t) t}=E e^{\widetilde{x} t} .
$$

With this definition the above criterion becomes equivalent to accepting the project if it satisfies condition $-e^{R(t) t}+Z \geq 0$. Since this is equivalent to $-1+Z e^{-R(t) t} \geq 0$, it is equivalent to accepting any risk-free investment project that has a nonnegative net present value, where rate $R(t)$ is used to discount cash-flows occurring at date $t$.

Proposition 1 Criterion 1 implies that any risk-free investment with a nonnegative net present value should be accepted, with an horizon-dependent discount rate $R(t)$ defined by (1).

It is interesting to examine how the discount rate to be used in costbenefit analysis is related to the time horizon. Our findings are summarized in the following Proposition.

Proposition 2 The socially efficient discount rate $R(t)$ is increasing with the time horizon $t$. It converges to the upper bound of the support of $\widetilde{x}$ as $t$ tends to infinity.

Proof: $R(t)$ can be seen as the certainty equivalent of the random payoff $\widetilde{x}$ for an agent with a constant absolute degree of risk aversion $-t$. As shown for example by Pratt (1964), a decrease in the degree of risk aversion, i.e., an increase in $t$, implies an increase in the certainty equivalent $R(t)$. The fact that $R(t)$ tends to the maximum of the support of $\widetilde{x}$ is well-known. It is the dual to the result that the certainty equivalent tends to the minimum possible payoff when risk aversion tends to infinity.

Thus, our recommendation is to take a larger interest rate to discount long-term cash-flows with respect to short-term ones. Moreover, as time horizon recedes to infinity, the discount rate should tend to the maximum possible rate.

\section{Post Scriptum}

Of course, this recommendation goes against many voices that rather suggest that we take a decreasing discount rate. Some scholars, such as Weitzman 
(1998, 2001), go to the extreme by suggesting a zero discount rate for far distant cash-flows. Implementing such a recommendation could have extreme consequences on how much effort our generation should exert to make far future generations better off, maybe at the expense of future generations that are closer to us.

Paradoxically, Weitzman (1998, 2001)'s argument is totally symmetric to ours. He considers the following decision criterion:

Criterion 2 Different investment projects should be ranked according to their expected net present value (ENPV).

This criterion yields an equivalent discount rate $R^{W}(t)$ that satisfies condition $E e^{-R^{W}(t) t}=E e^{-\widetilde{x} t}$. $R^{W}(t)$ is decreasing in $t$, and it tends to the minimum possible rate. Clearly, we cannot be both right. In fact, to tell the truth, I believe that we are both wrong, because our criteria are arbitrary, as they do not rely on actual preferences. For example, a third possible criterion would have been to rank investment projects on the basis of their expected returns. Using this criterion would yield an horizon-independent discount rate. By the way, this assumption corresponds in the theory of finance to the well-known Expectation Hypothesis. ${ }^{2}$

The question is whether the ENPV criterion or the ENFV criterion has any economic meaning when the risk is about the future economic environment. Taking the expected net future value is equivalent to assuming that all risks will be borne by the future generation. The current generation has a fixed budget for investing for the future. It only arbitrage among different investment strategies with the same initial cost. Using the expected net present value implicitly means that it is the current generation who bears the risk. As soon as $x$ will be know, the current generation will invest enough money to guarantee a sure payoff independent of $x$ for the future generation. Because the two approaches lead to radically different recommendations, we see that, to solve the problem, we cannot escape the discussion of who should bear which risk. The existing literature on the term structure of interest rates provides the relevant models to deal with these questions. It is true that these models are technical, but this is probably the cost to be paid to make policy recommendations that have an economic sense.

\footnotetext{
${ }^{2}$ For a discussion of this hypothesis, see for example Cochrane (2001), or Campbell, Lo and MacKinlay (1997).
} 


\section{REFERENCES}

Campbell, J.Y., A.W. Lo, and A.C. MacKinlay, (1997), The econometric of financial markets, Princeton University Press.

Cochrane, J., (2001), Asset Pricing, Princeton University Press.

Ingersoll, J.E., and S.A. Ross, (1992), Waiting to invest: Investment and uncertainty, Journal of Business, 65, 1-29.

Pratt, J., (1964), Risk aversion in the small and in the large, Econometrica, 32, 122-136.

Weitzman, M.L., (1998), Why the far-distant future should be discounted at its lowest possible rate?, Journal of Environmental Economics and Management, 36, 201-208.

Weitzman, M.L., (2001), Gamma discounting, American Economic Review, 91, 260-271. 